\title{
Percepções sobre aspectos da conservação dos quelônios na região do Baixo Xingu, Sudeste da Amazônia Brasileira
}

O aumento da compreensão dos papéis culturais, sociais e econômicos dos quelônios amazônicos é essencial para estabelecer planos de manejo e conservação eficazes. Nesse sentido, por meio de entrevistas semiestruturadas e da análise de conteúdo, o presente estudo avaliou percepções de moradores da região do baixo Xingu sobre aspectos relacionados à conservação dos quelônios. A maioria dos 55 moradores entrevistados considera que os quelônios têm grande importância cultural, social e ambiental; destaca costumes e falta de recursos financeiros como os principais motivos para os usos dos quelônios na região reconhece que as iniciativas conservacionistas desenvolvidas são eficazes, entretanto, afirma que os estoques naturais diminuíram ou estão diminuindo em razão da ação antrópica; participaria voluntariamente de ações para conservação dos quelônios, mas não incentivaria familiares e amigos a não consumirem esses répteis. Conhecimentos e atitudes a respeito dos quelônios estiveram relacionados às características socioeconômicas dos entrevistados. Os resultados sugerem que em razão do uso cultural como alimento e do comércio ilegal, os quelônios sofrem intensa pressão de caça. Assim como evidenciam a relevância dos aspectos culturais e socioeconômicos, envolvimento comunitário efetivo, geração de alternativas de renda e esforços educacionais contínuos para recuperação e manutenção das espécies de quelônios na região. Estudos futuros devem avaliar a longo prazo os efeitos dos usos e consumo desses répteis sobre seus estoques naturais, assim como aprofundar o conhecimento sobre como as variáveis socioeconômicas influenciam os hábitos e atitudes dos habitantes locais em relação a esses animais.

\section{Perceptions about aspects of chelonian conservation in the Lower Xingu region, Southeastern Brazilian Amazon}

\begin{abstract}
Increased understanding of the cultural, social and economic roles of Amazonian turtles is essential for establishing effective management and conservation plans In this sense, through semi-structured interviews and content analysis, the present study evaluated perceptions of residents of the lower Xingu region about aspects related to the conservation of turtles. Most of the 55 residents interviewed consider that turtles have great cultural, social and environmental importance highlights customs and lack of financial resources as the main reasons for the use of turtles in the region; recognizes that the conservation initiatives developed are effective, however, affirms that natural stocks have decreased or are decreasing due to anthropic action; I would voluntarily participate in actions to conserve turtles, but I would not encourage family and friends not to consume these reptiles. Knowledge and attitudes about turtles were related to the interviewees socioeconomic characteristics. The results suggest that due to the cultural use as food and the illegal trade, the turtles suffer intense hunting pressure. As well as showing the relevance of cultural and socioeconomic aspects, effective community involvement, generation of income alternatives and continuous educational efforts to recover and maintain the species of turtles in the region. Future studies should assess the long-term effects of the use and consumption of these reptiles on their natural stocks, as well as deepen the knowledge about how the socioeconomic variables influence the habits and attitudes of local inhabitants towards these animals.
\end{abstract}

Keywords: Socio-environmental importance; Ethnocognition; Attitudes; Testudines.

Topic: Uso de Recursos Naturais

Reviewed anonymously in the process of blind peer.
Received: 03/01/2021

Approved: 28/01/2021
Adson Gomes de Ataídes (iD

Universidade Federal do Tocantins, Brasil http://lattes.cnpq.br/9926543074591200 http://orcid.org/0000-0003-0380-3653

adson.gomes@yahoo.com.br

\section{Roberto Leandro Silva (iD}

Pontifícia Universidade Católica de Goiás, Brasil

http://lattes.cnpq.br/6874557633374460

http://orcid.org/0000-0003-3813-8622

robertosilva@nortesa.com.br

Adriana Malvasio (iD)

Universidade Federal do Tocantins, Brasil http://lattes.cnpq.br/9694032726460437

http://orcid.org/0000-0001-8020-3307

malvasio@uft.edu.br
6

DOI: 10.6008/CBPC2179-6858.2021.001.0053
Referencing this:

ATAÍDES, A. G.; SILVA, R. L.; MALVASIO, A.. Percepções sobre aspectos da conservação dos quelônios na região do Baixo Xingu, Sudeste da Amazônia Brasileira. Revista Ibero Americana de Ciências Ambientais, v.12, n.1, p.663-679, 2021. DOI: http://doi.org/10.6008/CBPC2179$\underline{6858.2021 .001 .0053}$ 


\section{INTRODUÇÃO}

O bioma amazônico é uma das áreas selvagens de maior riqueza de espécies de quelônios no mundo (MITTERMEIER et al., 2015). Nesse bioma, no território brasileiro são conhecidas 16 espécies de quelônios de água doce e duas terrestres (COSTA et al., 2018). Os quelônios amazônicos, sobretudo do gênero Podocnemis, constituem até hoje um recurso alimentar significativo e fonte de renda para as populações humanas que vivem ao longo dos rios, áreas rurais e pequenas cidades (SMITH, 1979; ALVES et al., 2012; PEZZUTI et al., 2018). Esses répteis também são uma parte considerável da biomassa faunística e desempenham importantes papéis no fornecimento de diversos serviços ecossistêmicos, especialmente relacionados à teia alimentar, ciclagem de matéria orgânica e dispersão de sementes (MOLL et al., 2004; FERRARA et al., 2017). As espécies de quelônios estão cada vez mais ameaçadas na Amazônia e fatores como a poluição das águas, a expansão das atividades agropecuárias, queimadas, desmatamentos das várzeas e matas ciliares, barramentos dos corpos d'água e a caça ilegal estão contribuindo para o declínio das populações desses répteis na região (RODRIGUES, 2005; ALHO et al., 2015). Como resultado desse cenário de múltiplas ameaças, quase a metade das 18 espécies de quelônios da Amazônia brasileira estão em alguma categoria de ameaça (IUCN, 2018).

Em resposta ao declínio das populações de quelônios, várias iniciativas de conservação foram implementadas na bacia Amazônica (PÁEZ et al., 2015). Entre essas iniciativas, destaca-se o hoje denominado Programa Quelônios da Amazônia - PQA, desenvolvido pelo governo brasileiro desde a década de 1970 e que realiza ações de proteção e manejo, especialmente das espécies do gênero Podocnemis, nos principais rios da Amazônia e do Centro Oeste do país (CANTARELLI et al., 2014). As estratégias de conservação desses répteis adotadas na Amazônia geralmente abrangem a proteção dos sítios de reprodução das espécies que desovam em praias e o monitoramento da população ou de fêmeas reprodutivas (FERRARA et al., 2017). Apesar dos esforços de conservação realizados pelo PQA e por várias outras instituições com iniciativas semelhantes, tem-se evidenciado declínios populacionais significativos de espécies de quelônios amazônicos (MITTERMEIER et al., 2004; PEZZUTI et al., 2010; EISEMBERG et al., 2019).

As atuais iniciativas conservacionistas desenvolvidas para a proteção das populações de quelônios na Amazônia, em parte não obtém resultados satisfatórios porque muitas vezes não integram as comunidades tradicionais e, além disso, desprezam seus conhecimentos e valores (REBÊLO et al., 2000; FACHÍN-TERAN, 2008; PÁEZ et al., 2015). Para que se alcancem melhores resultado, é necessário envolver as comunidades locais em todos os aspectos dos trabalhos de conservação, tornando-as participantes ativas no planejamento e execução das ações e fornecendo-lhes informações básicas sobre a história natural, ecologia e importância socioambiental das espécies (RUEDA-ALMONACID et al., 2007). Nesse sentido, os estudos de percepção ambiental são ferramentas importantes para se conhecer o que pensam as partes interessadas sobre os diversos aspectos da conservação dos quelônios e a partir disso estimular o envolvimento das comunidades locais. De acordo com Bennett (2016), as percepções podem e devem ser utilizadas para entender quando as avaliações das iniciativas conservacionistas são positivas ou negativas e para avaliar 
quais aspectos das ações desenvolvidas - impactos sociais, resultados ecológicos, gestão, entre outros - estão promovendo ou prejudicando o apoio comunitário.

Poucos são os trabalhos que avaliaram as percepções dos habitantes da região amazônica sobre ameaças, problemas e soluções relacionados à conservação dos quelônios. Sobre esse assunto, estudos avaliaram as percepções de alunos do ensino fundamental (SILVA et al., 2012; CARVALHO et al., 2016; ATAÍDES et al., 2019) e de moradores de comunidades tradicionais, áreas rurais e urbanas (REBÊLO et al., 2000; ATAÍDES et al., 2010; FERRONATO et al., 2013; PANTOJA-LIMA et al., 2014; FARIA et al., 2018). A recuperação e manutenção dos índices populacionais de quelônios amazônicos a níveis desejáveis dependem da continuidade, aprimoramento e ampliação dos trabalhos de proteção, manejo e pesquisa com esses animais (SALERA JÚNIOR et al., 2016). Nesse sentido, o presente estudo pretende avaliar as percepções de moradores da região do baixo Xingu sobre a importância socioambiental, principais usos, conflitos, estoques naturais, ameaças, o que fazer para conservar e eficácia dos projetos de conservação dos quelônios. Assim como, levando-se em consideração variáveis socioeconômicas, verificar se existem diferenças nas percepções e atitudes a respeito desses répteis.

\section{MATERIAIS E MÉTODOS}

\section{Área de estudo}

O estudo foi realizado em áreas urbanas e comunidades ribeirinhas dos municípios de Altamira, Vitória do Xingu e Senador José Porfírio, localizados no sudoeste do Estado do Pará (Figura 1). Esses municípios em conjunto ocupam área aproximada de 177042 km² e possuem população estimada em 141386 habitantes (IBGE, 2019). A base da economia da região são as atividades agropecuárias, com destaque para pecuária bovina e o plantio de cacau, banana e café (PARÁ, 2010).

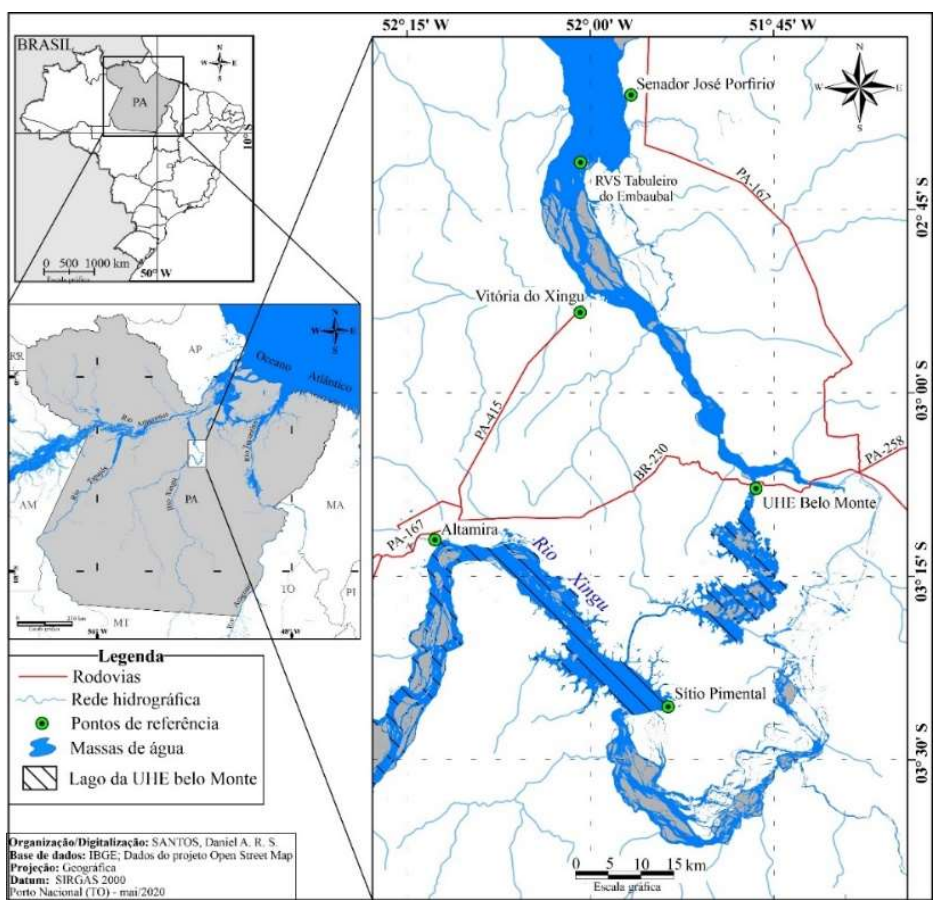

Figura 1: Localização da área de estudo nos municípios de Altamira, Vitória do Xingu e Senador José Porfírio, região do baixo Xingu, sudoeste do Estado do Pará, Brasil. 
Essa região está sob influência direta e indireta de grandes projetos de infraestrutura como da pavimentação da Rodovia Transamazônica, da construção/operação da Usina Hidrelétrica Belo Monte, da implantação da Linha de Transmissão Tucuruí-Altamira-Macapá-Manaus; e do projeto de exploração de ouro da Belo Sun Mineração (PARÁ, 2015). A área de estudo também está situada na região hidrográfica do baixo Xingu e abrange o Arquipélago do Embaubal. As ilhas ali existentes são formadas com a deposição de sedimentos transportados pela dinâmica ambiental do rio Xingu, constituindo um ambiente de elevada diversidade biológica e beleza cênica surpreendente (PAULA et al., 2014). O conjunto de praias dessa região é um dos principais sítios reprodutivos dos quelônios do gênero Podocnemis na América do Sul (PEZZUTI et al., 2008).

\section{Coleta de dados}

Os dados foram coletados no período de março a dezembro de 2017, por meio de entrevistas semiestruturadas. Esse método de pesquisa é amplamente empregado para a coleta de dados qualitativos e possibilita uma compreensão detalhada das crenças, atitudes, valores e motivações, em relação aos comportamentos das pessoas em contextos sociais específicos (BAUER et al., 2002). As entrevistas foram realizadas a partir de um tópico guia, elaborado conforme Ditt et al. (2003) e que continha questões sobre o perfil socioeconômico dos participantes e conhecimentos e atitudes em relação aos quelônios. Os diálogos foram registrados com gravador de áudio digital.

A técnica não-probabilística denominada "snowball sampling" foi utilizada para selecionar os entrevistados. Essa técnica consiste em identificar e entrevistar informantes-chave que indicam novos participantes, que por sua vez indicam outros, e assim sucessivamente, até que não se tenha novos participantes ou os indicados passem a repetir os conteúdos já obtidos em entrevistas anteriores, sem acrescentar informações relevantes para pesquisa (VINUTO, 2014). Foram entrevistados de maneira individual moradores de áreas urbanas e comunidades ribeirinhas. Os participantes assinaram um termo de consentimento e livre esclarecido permitindo a realização da entrevista e sendo informados dos objetivos da pesquisa, confidencialidade e privacidade dos informantes, bem como possibilitando que se recusassem a participar ou retirassem seu consentimento em qualquer fase do estudo.

\section{Análise dos dados}

As informações transcritas dos áudios das entrevistas foram avaliadas por meio do método de Análise de Conteúdo. Esse método é composto por um conjunto de técnicas de pesquisa que permite reconstruir indicadores e cosmovisões, valores, atitudes, opiniões, preconceitos e estereótipos e compará-los entre comunidades (BARDIN, 1977; BAUER et al., 2002). Dentro dessa análise, foram empregados os procedimentos indicados por Gomes (2007): decomposição do material a ser analisado em partes; distribuição das partes em categorias; e descrição, inferência e interpretação dos resultados.

As respostas para a questão fechada relacionada à disposição dos entrevistados em incentivar familiares e amigos a não consumirem os quelônios, também foram analisadas conforme Ditt et al. (2003), 
atribuindo-se rótulos numéricos aos dados qualitativos. Os rótulos atribuídos seguiram uma escala tipo Likert composta por pontuações distintas e ordinais (LIKERT, 1932), variando de 1 (para respostas com menor interesse na conservação dos quelônios) a 5 (para respostas com maior grau de conhecimento sobre os quelônios e interesse na conservação). Para as questões abertas, sobre o conhecimento da importância social e ambiental dos quelônios, os escores foram estabelecidos após comparação das diversas respostas obtidas e seguindo o mesmo critério da questão fechada. Para verificar se existiam diferenças nas percepções e atitudes levando-se em consideração a idade, escolaridade, profissão, local de residência e renda por pessoa da família dos entrevistados, as pontuações atribuídas às respostas foram comparadas por meio do Teste $U$ de Mann-Whitney. A hipótese nula foi que o conhecimento e atitudes em relação aos quelônios independem das variáveis socioeconômicas. Os procedimentos estatísticos foram realizados no programa BioEstat 5.0 (AYRES et al., 2007), considerando-se significativos os resultados com probabilidade menor que 0.05 ( $p<$ 0.05).

\section{RESULTADOS E DISCUSSÃO}

Foram entrevistados 55 moradores da área de estudo. Eles tinham em média 42.64 anos de idade, famílias com renda mensal de 1.97 salários mínimos e compostas por 4.49 pessoas; a maioria era do sexo masculino (83.64\%), não foi alfabetizada ou tinha de um a nove anos de escolaridade $(61.82 \%)$, exercia a profissão de pescador (38.18\%) e residia em comunidades ribeirinhas (52.73\%) (Tabela 1). Embora o número de participantes não corresponda a uma amostra quantitativamente representativa do total de habitantes da área de estudo, de acordo com a literatura avaliações qualitativas devem envolver de 30 a 50 entrevistados (MORSE, 1994; MORSE, 2000; GUEST et al., 2006). Além disso, destaca-se que os entrevistados no presente estudo têm perfis diversos e que outras pesquisas sobre percepções em relação aos quelônios envolveram quantidades de participantes semelhantes ou menores (REBÊLO et al., 2000; ATAÍDES et al., 2010; FERRONATO et al., 2013; NORRIS et al., 2013; OCAMPO-GONZÁLEZ et al., 2018).

Tabela 1: Perfil socioeconômico dos entrevistados nos municípios de Altamira, Vitória do Xingu e Senador José Porfírio, sudoeste do Estado do Pará, Brasil. n: número de entrevistados.

\begin{tabular}{|c|c|}
\hline Variável & Valores \\
\hline Gênero (n, \%) & masculino $(46,83.64)$, feminino $(9,16.36)$ \\
\hline Idade em anos (média, mínimo - máximo) & $42.64,21-78$ \\
\hline Escolaridade (n, \%) & $\begin{array}{l}\text { não alfabetizado }(10,18.18),<6 \text { anos }(17,30.91), 6 \text { a } 9 \text { anos }(7,12.73), 10 \text { a } 12 \text { anos } \\
(13,23.64),>12 \text { anos }(8,14.54)\end{array}$ \\
\hline Profissão (n, \%) & pescador $(21,38.18)$, outras $(34,61.82)$ \\
\hline Local de residência (n, \%) & cidade $(26,47.27)$, comunidade ribeirinha $(29,52.73)$ \\
\hline $\begin{array}{l}\text { Número de membros da família (média, } \\
\text { mínimo - máximo) }\end{array}$ & $4.49,1-14$ \\
\hline $\begin{array}{l}\text { Renda familiar mensal (média, mínimo - } \\
\text { máximo) }\end{array}$ & $1.97,0.5-6.4$ \\
\hline
\end{tabular}

\section{Conhecimento sobre diversidade de espécies e importância dos quelônios}

A maioria dos entrevistados (87.27\%) mostrou conhecimento razoável sobre a diversidade de quelônios na área de estudo, citando de três a sete espécies com ocorrência na região. Foram mencionadas com maior frequência Podocnemis unifilis (25.87\%), seguida de $P$. expansa (24.88\%) e $P$. sextuberculata 
(19.90\%) (Tabela 2). Na Amazônia brasileira estão distribuídas 16 espécies de quelônios de água doce e duas terrestres (COSTA et al., 2018), sendo que para a região do baixo Xingu há registros confirmados da ocorrência de dez dessas espécies (PEZZUTI et al., 2008). Citadas com maior frequência pelos entrevistados, $P$. unifilis, $P$. expansa e $P$. sextuberculata, de acordo com a literatura, estão entre as espécies de quelônios amazônicos que sofrem maior pressão de caça (VALSECCHI et al., 2009; CASAL et al., 2013; PANTOJA-LIMA et al., 2014).

Tabela 2: Espécies de quelônios e frequência percentual com que foram citadas pelos entrevistados nos municípios de Altamira, Vitória do Xingu e Senador José Porfírio, sudoeste do Estado do Pará, Brasil.

\begin{tabular}{lll}
\hline Táxon & Nome local & Frequência de citações (\%) \\
\hline Podocnemis unifilis & Tracajá, Zé prego & 25,87 \\
Podocnemis expansa & Tartaruga & 24,88 \\
Podocnemis sextuberculata & Pitiú, Cambéu & 19,90 \\
Chelonoidis spp. & Jabuti & 9,95 \\
Peltocephalus dumerilianus & Cabeçudo & 8,46 \\
Rhinoclemmys punctularia & Perema & 6,97 \\
Mesoclemmys gibba & Cabeça torta, Lalá & 1,99 \\
Chelus fimbriatus & Mata-matá & 1,49 \\
Platemys platycephala & Jabuti machado & 0,50 \\
\hline
\end{tabular}

Os entrevistados foram quase unânimes $(98,18 \%)$ em responder que os quelônios são muito ou extremamente importantes para os moradores da região. A maioria (70.91\%) informou de uma a três razões para justificar a grande importância social desses répteis e o restante (29.09\%) não soube responder. De acordo com os entrevistados, esses animais são relevantes do ponto de vista social por serem: utilizados na alimentação dos moradores da região (60.71\%), uma alternativa de renda a partir do comércio ilegal (19.64\%), parte da cultura (7.14\%), atração turística (7.14\%), bonitos (3.57\%) e/ou criados em cativeiros por muitos (1.79\%). Justificando a importância social desses répteis, o entrevistado E43, pescador, com 63 anos de idade, respondeu:

(Os quelônios são importantes para os moradores da região) porque eles produzem bem. As pessoas as vezes arranca (retiram os ovos dos ninhos) pá comer. Outros arranca pá vender. Agora aí eu acho um erro, pelo menos aqui nessa área que está acabando. Agora para nós, que pescava pá comer, eu achava bom demais. Mas não podia trazer (para cidade). Nós nunca trouxemos... agora os cabôco (outras pessoas) pega bem. Os cabôco pega e faz é vender lá. Eles vendem de 30 (reais), 40 (reais), depende do tamaim (tamanho) delas. (Existem compradores?) Mar menino, todo mundo gosta de tracajá. Se acabar as tracajá e tartaruga, acabou a alegria nossa. Nós que nascemos e se criemos no beradão (margens do rio) é muito difícil um para não gostar de ovo. Eu pelo menos gosto demais.

Esses resultados corroboram com a informação de que os quelônios amazônicos, em especial as espécies do gênero Podocnemis, constituem até hoje um recurso alimentar significativo para as populações ribeirinhas e com alguma importância econômica em pequenas cidades do interior (REBÊLO et al., 2000; FARIA et al., 2018; PEZZUTI et al., 2018; SCHNEIDER et al., 2011; SCHNEIDER et al., 2016). Pantoja-Lima et al. (2014), por exemplo, estimaram que 34 toneladas de Podocnemis foram comercializadas ilegalmente em apenas um ano no município de Tapauá, interior do Estado do Amazonas, com as famílias pagando até o equivalente a US $\$ 219,29$ pelo total de animais que cada uma consumiu naquele período. Na região amazônica também são consumidas espécies como Peltocephalus dumerilianus (FÉLIX-SILVA et al., 2019), Kinosternon scorpioides (CRISTO et al., 2017) e Chelonoidis spp. (MORCATTY et al., 2015). 
Quase todos os entrevistados (98.11\%) também consideram os quelônios muito ou extremamente importantes do ponto de vista ambiental. A maioria (60.00\%) informou uma ou duas razões para justificar a importância ecológica desses répteis e o restante $(40.00 \%)$ não soube responder. Responderam que os quelônios são importantes porque desempenham funções ecológicas como parte da teia alimentar, na manutenção do equilíbrio ambiental, ciclagem de matéria orgânica ou dispersão de sementes (59.46\%); fazem parte da natureza (35.14\%); ou porque foram criados por Deus (5.40\%). De maneira semelhante, em estudo envolvendo a percepção de moradores sobre tartarugas de água doce em uma área de proteção ambiental no México, Ocampo-González et al. (2018) verificaram que 79,62\% ( $n=42)$ dos entrevistados atribuíram importância a esses répteis por estarem em risco de extinção, bem como ajudarem na conservação do ecossistema, equilíbrio da cadeia alimentar e manutenção dos rios e lagos.

Apesar de serem quase unânimes em afirmar que os quelônios são muito importantes, uma parte considerável dos entrevistados não soube responder porque esses animais são relevantes para as pessoas que moram na região e meio ambiente. É essencial que ações voltadas para conservação dos quelônios amazônicos aumentem a compreensão dos atores envolvidos sobre a importância social, econômica e ecológica desses animais (BALESTRA, 2016; SCHNEIDER et al., 2011), uma vez que esse conhecimento pode contribuir com a obtenção de melhores resultados nas iniciativas conservacionistas (VALLEJO-BETANCUR et al., 2018). Os resultados positivos obtidos pelo Programa Nacional de Conservação de Tartarugas Marinhas - TAMAR na área da Praia do Forte, nordeste do Brasil, por exemplo, foram atribuídos a mudanças de atitudes em relação às tartarugas e a redução do consumo direto desses animais, sendo que na opinião da maioria dos moradores da área, tais mudanças ocorreram porque começaram a ter conhecimento da importância do ecoturismo das tartarugas marinhas na economia local (PEGAS et al., 2010).

Não houve diferença na compreensão da importância social dos quelônios segundo a idade $(U=$ 323.50, $p=0.3589)$, escolaridade $(U=371.00, p=0.9062)$, profissão $(U=265.50, p=0.1129)$, local de residência $(U=271.00, p=0.0739)$ e renda $(U=345.00, p=0.5896)$ dos entrevistados. Os usos e consumo dos quelônios amazônicos fazem parte da cultura local, e isso pode ser o motivo do conhecimento sobre a relevância social desses répteis não estar relacionado às variáveis socioeconômicas avaliadas no presente estudo. Em relação ao conhecimento sobre a importância ambiental dos quelônios, verificou-se diferença apenas quando se comparou as respostas dos entrevistados de acordo com a renda (Tabela 3). A pontuação média sobre esse assunto aumentou de 1.51 entre os entrevistados com renda $\leq 0.5$ salários mínimos para 1.84 entre os que tinham renda > 0.5 salários, o que pode ser explicado pelo fato de teoricamente as pessoas com maior renda terem mais acesso a informações de maneira geral, independentemente do grau de instrução. Damasio et al. (2012) verificaram que o conhecimento ecológico de pescadores no litoral norte de São Paulo sobre tartarugas marinhas variou de acordo com a idade, escolaridade e anos de pesca desses profissionais, sendo que os mais jovens e com mais anos de estudo tinham maior conhecimento sobre aspectos da ecologia das tartarugas. Eles explicaram que esse resultado pode ter sido influenciado pelo maior acesso dos mais jovens a programas de conservação e educação ambiental desenvolvidos na região. 
Tabela 3: Comparação do conhecimento dos entrevistados sobre a importância ambiental dos quelônios nos municípios de Altamira, Vitória do Xingu e Senador José Porfírio, sudoeste do Estado do Pará, Brasil. n: número de entrevistados.

\begin{tabular}{lll}
\hline Variável & Grupos $(\mathbf{n}$, pontuação média) & Teste Mann-Whitney \\
\hline Idade & $\leq 42$ anos $(28,1.64),>42$ anos $(27,1.70)$ & $U=348.00, p=0.6135$ \\
Escolaridade & $<6$ anos $(27,1.55), \geq 6$ anos $(28,1.78)$ & $U=297.00, p=0.1727$ \\
Profissão & pescador $(21,1.52)$, outra $(34,1.76)$ & $U=282.00, p=0.1969$ \\
Local de residência & cidade $(26,1.77)$, comunidade $(29,1.58)$ & $U=323.00, p=0.3626$ \\
Renda por pessoa & $\leq 0.5$ salários $(29,1.51),>0.5$ salários $(26,1.84)$ & $U=254.00, p=0.0381$ \\
\hline
\end{tabular}

\section{Principais usos dos quelônios}

A maior parte (90.91\%) dos entrevistados citou de um a três principais usos dos quelônios na região e o restante (9.09\%) não soube responder. Esses répteis são utilizados sobretudo na alimentação (68.11\%), mas também como fonte de renda a partir do comércio ilegal (23.19\%), como zooterápico $(5.80 \%)$ e/ou animal de estimação (2.90\%). Ao serem indagados sobre o que motiva esses usos, afirmaram que: as pessoas gostam ou estão acostumadas a comer esses animais e os ovos (46.15\%); usam como alimento ou vendem por necessidade (17.31\%); capturaram e vendem facilmente (7.70\%); existem compradores (3.85\%); servem para variar a dieta (1.92\%); e/ou falta fiscalização (1.92\%); e os demais (21.15\%) não souberam responder. Explicando que a motivação para uso desses animais como alimento é cultural, o entrevistado E4, comerciante, com 54 anos de idade, afirmou:

Eu acho que é o hábito do ribeirinho mesmo. As pessoas foram criadas comendo esses bichos aí. Então eles já têm aquele hábito de comer o tracajá né. Comer a tartaruga. Porque para eles é muito gostoso né. Eles gostam muito. Então eles já foram criados aí, comendo esses bichos aí. Desde quando os pessoais começaram a abrir isso aqui (habitar a região), os pessoais começaram a comer isso aí. Agora não tem jeito mais não, o menino foi criado comendo tracajá e come tracajá até morrer. Acha gostoso né.

Os quelônios são um importante recurso alimentar para os habitantes da região amazônica desde antes da chegada dos europeus (KLEMENS et al., 1995). Atualmente, esses répteis continuam a ser utilizados pelas populações humanas que vivem ao longo dos rios na Amazônia, sobretudo como uma fonte de alimento e alternativa de renda a partir do comércio ilegal (SCHNEIDER et al., 2011; SCHNEIDER et al., 2016; FARIA et al., 2018; PEZZUTI et al., 2018), o que também foi verificado no presente estudo. A opinião dos entrevistados sobre a motivação desses usos é corroborada por diversos autores que apontaram a cultura e a falta de recursos financeiros, respectivamente, entre os principais motivos para o uso dos quelônios como alimento e na obtenção de renda a partir do comércio ilegal (CASAL et al., 2013; PANTOJA-LIMA et al., 2014). Assim como verificado por Ferronato et al. (2013), foi baixo o percentual de pessoas no presente estudo que relatou usos medicinais dos quelônios, tendo sido citado o uso da banha de tartaruga para o tratamento de inchaço, tosse ou como cosmético para os cabelos. Também foi pequeno o percentual de entrevistados que mencionou o uso desses répteis como animal de estimação, o que foi justificado pelo receio de ser multado pelos órgãos de fiscalização ambiental. De modo contrário, outros estudos constataram que esses répteis são importantes zooterápicos e frequentemente mantidos como animais de estimação (PEZZUTI et al., 2010; ATAÍDES et al., 2010; ALVES et al., 2012). 


\section{Conflitos, estoques naturais, principais ameaças e o que fazer para conservar}

Verificou-se que pouco mais da metade (63.64\%) dos entrevistados respondeu não existirem conflitos relacionados aos quelônios na região. Os demais (36.36\%), por outro lado, afirmaram que existem conflitos entre quem consome/vende esses animais e os agentes de fiscalização a serviço dos órgãos ambientais. Dentre os que indicaram a existência desse problema, argumentou-se que os desentendimentos poderiam ser resolvidos se houvesse mais orientação e diálogo por parte dos agentes de fiscalização (50.00\%), se fosse garantido o direito ao consumo de subsistência $(25.00 \%)$ ou se existissem cotas para consumo/venda (8.33\%), e outros não souberam como solucionar (16.67\%). Silva (2007) salienta que o consumo de quelônios na região amazônica ocorre em um contexto de rigorosa proibição legal e de conflitos com as agências ambientais governamentais. Nesse sentido, é essencial que os hábitos culturais, necessidades alimentares e financeiras locais sejam levados em consideração nos programas de conservação e na implementação de leis relacionadas ao consumo de quelônios (PANTOJA-LIMA et al., 2014; MORCATTY et al., 2015).

A maioria (52.73\%) afirmou que os estoques naturais de quelônios na região diminuíram ou estão diminuindo. Os demais responderam que esses estoques aumentaram ou estão aumentando (21.82\%), estão normais $(7.27 \%)$ ou não souberam responder (18.18\%). Além disso, a percepção de que existem ameaças à conservação dos quelônios na região é majoritária (85.45\%) entre os entrevistados. Foram citadas como ameaças: a predação antrópica (62.07\%), a degradação ambiental - por meio das queimadas, desmatamentos, poluição ou seca dos rios (20.69\%), a barragem hidrelétrica (10.34\%), a predação natural (3.45\%) e/ou as embarcações que trafegam pelos rios e causam lesões ou morte desses répteis (3.45\%). 0 entrevistado E12, pescador, com 56 anos de idade, respondeu que existem ameaças à conservação desses animais e explicou:

Porque se elas, por exemplo, que nem ali na praia que elas fazem arribação (nidificam em bandos). Que lá elas arribam de dia, aquela grande quantidade. Se ali não tiver uma proteção do Ibama lá, o povo pega tudo aquela tartaruga que sobe né. Agarra tudo e aí não tem como elas reproduzir né. Esse pessoal, se ele chegar numa praia dessa e tiver cheio de tartaruga, o povo pega tudinho.

A maioria (94.55\%) dos participantes citou de uma a três maneiras de garantir a conservação dos quelônios, enquanto alguns (5.45\%) não souberam responder. As medidas para conservação mais citadas foram: fiscalizar ou aumentar a fiscalização sobre a captura/coleta/comércio ilegal dos quelônios e seus ovos (36.92\%); realizar projetos de conservação que incluam a proteção das praias de desova e manejo dos ninhos e filhotes (20.00\%); e realizar ações de educação ambiental para orientar e conscientizar as pessoas (18.46\%) (Tabela 4). A maioria (53.70\%) dos entrevistados cita apenas os órgãos ambientais (municipal, estadual ou federal) como responsáveis pela conservação, outros $29.63 \%$ citam somente as pessoas e $16.67 \%$ afirmam que a responsabilidade pela conservação é tanto das pessoas quanto dos órgãos ambientais.

Diversos autores corroboram a percepção dos entrevistados no presente estudo em relação aos estoques naturais dos quelônios amazônicos, ao afirmarem que é evidente o declínio das populações desses répteis, especialmente de podocnemidídeos (MITTERMEIER et al., 2004; PEZZUTI et al., 2010; EISEMBERG et 
al., 2019). Além disso, a predação antrópica e a perda e degradação do habitat também foram percebidos por entrevistados em outros estudos como principais riscos à conservação dos quelônios (ATAÍDES et al., 2010; VALLEJO-BETANCUR et al., 2018). De acordo com a literatura, a poluição das águas, expansão das atividades agropecuárias, queimadas, desmatamentos das várzeas e matas ciliares, barramentos dos corpos d'água e a caça ilegal estão entre as principais ameaças à manutenção das populações dos quelônios amazônicos (RODRIGUES, 2005; ALHO et al., 2015).

Tabela 4: Respostas dos entrevistados sobre o que fazer para conservar os quelônios nos municípios de Altamira, Vitória do Xingu e Senador José Porfírio, sudoeste do Estado do Pará, Brasil.

\begin{tabular}{ll}
\hline Categoria & $\%$ \\
\hline Fiscalizar ou aumentar a fiscalização & 36,92 \\
Realizar projetos de conservação que incluam a proteção das praias de desova e o manejo dos ninhos e filhotes & 20,00 \\
Realizar ações de educação ambiental & 18,46 \\
Gerar trabalho e renda para a população ribeirinha & 6,15 \\
Conservar os habitats ou não queimar, desmatar, poluir & 6,15 \\
Envolver a população nas iniciativas de conservação & 4,62 \\
Cumprir a lei & 4,62 \\
Estabelecer cotas de uso & 3,08 \\
\hline
\end{tabular}

É provável que os entrevistados não se vejam como parte da solução para as questões ligadas à proteção dos quelônios amazônicos, uma vez que a maioria citou a fiscalização sobre o consumo e comércio ilegais como meio de garantir a conservação desses animais e mencionou apenas os órgãos ambientais como responsáveis por essa tarefa. Fatores econômicos e culturais podem estar relacionados a essa visão distanciada sobre as possíveis medidas de conservação, uma vez que muitos precisam se preocupar em primeiro lugar em como manter a família e também estão habituados a consumir esses animais. Nesse sentido, iniciativas de conservação devem explicar as vantagens e importância da conservação, bem como propiciar alternativas de geração de renda para os habitantes da região (CONWAY-GÓMEZ, 2008; SCHNEIDER et al., 2011).

\section{Eficácia dos projetos de conservação}

O Tabuleiro do Embaubal é uma das 11 localidades, em nove estados brasileiros, onde se desenvolvem as ações de proteção e manejo do PQA (EISEMBERG et al., 2019), as quais desde o ano de 2011 vem sendo realizadas em conjunto com o Programa de Conservação e Manejo de Quelônios UHE Belo Monte, conduzido pela empresa Norte Energia S.A. Na opinião da maior parte (74.51\%) dos entrevistados, os projetos de conservação/manejo desenvolvidos na região são eficazes na recuperação e manutenção dos estoques naturais dos quelônios, tendo em vista que protegem/aumentam a produção de filhotes, protegem as fêmeas e ovos da predação antrópica ou sensibilizam/conscientizam as pessoas sobre a importância da conservação desses répteis. Os demais informantes não souberam responder porque os projetos são eficazes (17.65\%); afirmaram que ajudam em parte, pois, não valorizam a experiência dos moradores da região (3.92\%); ou não contribuem para conservação, pois, são ineficazes na fiscalização e as pessoas continuam pescando esses animais (3.92\%). De maneira semelhante ao presente estudo, Vallejo-Betancur et al. (2018) verificaram que $84 \%(n=42)$ dos entrevistados em estudo realizado no norte da Colômbia avaliaram 
positivamente as iniciativas voltadas para a conservação de tartarugas. No Brasil, o trabalho realizado pelo PQA tem contribuído para manutenção das populações de algumas das espécies alvo nas áreas em que é desenvolvido e, em quatro décadas de execução, já devolveu ao hábitat natural mais de 70 milhões de filhotes das espécies P. expansa, P. unifilis e P. sextuberculata (FAGUNDES et al., 2019).

Embora poucos entrevistados no presente estudo tenham expressado esta opinião, é importante destacar que alguns autores consideram que parte dos projetos conservacionistas tem eficácia limitada, pois, muitas vezes não contam com a participação comunitária (REBÊLO et al., 2000; FACHÍN-TERAN, 2008; PÁEZ et al., 2015; SALERA JÚNIOR et al., 2016). O envolvimento e apoio dos habitantes locais são essenciais nas estratégias de conservação dos quelônios. É necessário envolver as comunidades locais em todos os aspectos dos trabalhos de conservação, tornando-as participantes ativas no planejamento e execução das ações e fornecendo-Ihes informações básicas sobre a história natural, ecologia e importância socioambiental das espécies (REBÊLO et al., 2000; FACHÍN-TERAN, 2008). A participação da comunidade, se implementada adequadamente, também pode facilitar o gerenciamento eficaz de recursos naturais onde a aplicação da lei é limitada ou ineficaz (CAMPOS-SILVA et al., 2018; NORRIS et al., 2018). Ademais, experiências de gestão de recursos naturais baseadas na comunidade desencadeiam o desenvolvimento de conhecimento, mudanças de valores e aprendizagem social, que podem servir de exemplo para outras iniciativas (PEZZUTI et al., 2018).

\section{Atitudes em relação aos quelônios}

A maioria (83.64\%) dos entrevistados respondeu que participaria de maneira voluntária de ações voltadas para a conservação dos quelônios; enquanto os demais (16.36\%) disseram que não participariam ou estavam indecisos em relação a essa questão. Os entrevistados explicaram que estavam dispostos a participar porque gostariam de conservar esses animais para as gerações futuras ou caso contrário serão extintos (64.44\%); ou porque gostam das atividades, acham os quelônios bonitos, aprendem ou se divertem muito (20.00\%). Os demais responderam que não estavam interessados em participar, devido a indisponibilidade de tempo (11.11\%) ou porque não queriam se indispor com amigos/vizinhos (4.45\%). Na mesma área do presente estudo e avaliando os efeitos de práticas de educação ambiental entre alunos do ensino fundamental, Ataídes et al. (2019) verificaram que a maioria dos estudantes $(85.32 \%, n=157)$ também se mostrou interessada em participar de atividades voltadas para a proteção dos quelônios e alegou que esses répteis são importantes para o meio ambiente, cultura, podem ser extintos ou que gostaria de aumentar o conhecimento sobre esses animais. De maneira semelhante, Pezzuti et al. (2018) relataram que apesar dos altos riscos e benefícios materiais limitados, moradores de comunidades no baixo Amazonas, motivados por uma combinação de valores materiais, sociais e simbólicos, continuavam a participar do gerenciamento dos locais de nidificação de tartarugas.

A maior parte (36.36\%) dos entrevistados afirmou que não incentivaria familiares/amigos a não comer a carne/ovos de quelônios, pois, não seria atendida; é difícil mudar o costume; não gostaria de se indispor com as pessoas; muitos comem por necessidade; ou porque também faz uso desses répteis como alimento. Outros (32.73\%) responderam que incentivariam, pois, devemos conservar/proteger; gostariam de 
conservar para as gerações futuras também conhecerem; ou porque de modo contrário esses animais serão extintos. Alguns (12.73\%) não souberam responder; ou informaram que concordam com o consumo de subsistência (9.09\%); ou que são animais protegidos por lei (5.45\%); ou que não concordam com o consumo de ovos e filhotes (3.64\%). O entrevistado E38, pescador, com 60 anos de idade, respondeu que é difícil convencer as pessoas a não comerem a carne/ovos dos quelônios e explicou:

Tem muita gente que come mermo. Eles se alimentam. Se sustenta. Às vezes eles não arruma outra coisa e aí você, por exemplo, você não vai ver seu filho chorando com fome e não tentar ver se ele se alimenta. Porque é triste a pessoa com fome. É triste. Principalmente às vezes uma criança não tem o que comer, está com fome né.

Assim como verificado no presente estudo, alunos do ensino fundamental informaram que os costumes e a falta de renda são os principais obstáculos para convencer os moradores da região do presente estudo a mudarem os hábitos em relação aos quelônios (ATAÍDES et al., 2019). A importância cultural da espécie deve ser considerada como um aspecto de alta relevância nas estratégias de conservação concebidas para áreas onde o uso de recursos naturais é crítico para subsistência dos habitantes locais (FREITAS et al., 2020). Espécies culturalmente importantes são ferramentas de conservação eficazes, não só das espécies alvo, mas também dos ecossistemas associados, uma vez que estimulam o interesse e o envolvimento efetivo da comunidade nas ações propostas (CAMPOS-SILVA et al., 2018). A geração de fontes alternativas de renda também é um fator importante para garantir a participação comunitária e o compromisso de longo prazo com as ações de conservação, tendo em vista que pode contribuir com a redução da caça furtiva e para tornar as atividades menos vulneráveis a variações de interesses (FREITAS et al., 2020).

As ações de educação ambiental são igualmente imprescindíveis nas estratégias de conservação dos quelônios, na medida em que estimulam a participação comunitária efetiva, sensibilizam, promovem relações de afetividade e contribuem para mudança de valores e atitudes em relação a esses animais (RODRIGUES, 2005; RUEDA-ALMONACID et al., 2007; SCHNEIDER et al., 2011). Vallejo-Betancur et al. (2018), por exemplo, verificaram que pessoas expostas a iniciativas de conservação, incluindo programas de educação ambiental nas escolas, fizeram menos uso direto de quelônios no norte da Colômbia. Esforços educacionais também foram capazes de modificar as atitudes e comportamentos das pessoas em relação às tartarugas marinhas, colaborando para manutenção dos estoques naturais das espécies (TISDELL et al., 2005; ZEPPEL, 2008; LEWIS et al., 2010; SILVA et al., 2014).

No presente estudo, a disposição em incentivar familiares e amigos a não consumir a carne e/ou ovos de quelônios foi maior entre os entrevistados mais jovens, com maior escolaridade, que não eram pescadores e que moravam na cidade, mas não variou levando-se em consideração a renda (Tabela 5). As atitudes e hábitos relacionados ao consumo/venda de quelônios podem ser influenciados por variáveis socioeconômicas. Por exemplo, é comum a suposição de que pessoas com alta escolaridade fazem menos ou nenhum uso de tartarugas (REBÊLO et al., 2000; SCHNEIDER et al., 2011). Morcatty et al. (2015), em pesquisa realizada na região do médio Amazonas, constataram que a caça e o comércio ilegal de Chelonoidis denticulata são fortemente influenciados por fatores sociais e ambientais, sendo que enquanto nas comunidades de florestas de terras altas a motivação para a caça dessa espécie era o consumo de 
subsistência, nas comunidades de florestas inundadas era principalmente obter recursos financeiros. De modo diferente do verificado no presente estudo, Conway-Gómez (2008) observou que existe uma relação negativa inversa entre a renda das pessoas e o consumo/comércio ilegal de tartarugas. Por outro lado, Norris et al. (2013) destacaram que as variáveis econômicas e sociais tiveram baixa importância na explicação do consumo de ovos de Podocnemis unifilis por moradores do entorno de uma área protegida de uso sustentável no leste da Amazônia brasileira, e afirmaram que entender o contexto socioeconômico local e as atitudes das partes interessadas deve ser uma prioridade para garantir o sucesso das atividades de conservação.

Tabela 5: Comparação da disposição dos entrevistados em incentivar o não consumo dos quelônios nos municípios de Altamira, Vitória do Xingu e Senador José Porfírio, sudoeste do Estado do Pará, Brasil. n: número de entrevistados.

\begin{tabular}{lll}
\hline Variável & Grupos (n, pontuação média) & Teste Mann-Whitney \\
\hline Idade & $\leq 42 \operatorname{anos}(28,3.78),>42$ anos $(27,2.96)$ & $U=251.00, p=0.0325$ \\
Escolaridade & $<6$ anos $(27,2.96), \geq 6$ anos $(28,3.78)$ & $U=259.00, p=0.0451$ \\
Profissão & pescador $(21,2.76)$, outra $(34,3.76)$ & $U=225.50, p=0.0260$ \\
Local de residência & cidade $(26,4.15)$, comunidade $(29,2.68)$ & $U=168.50, p=0.0004$ \\
Renda por pessoa & $\leq 0.5$ salários $(29,3.24),>0.5$ salários $(26,3.53)$ & $U=340.00, p=0.5328$ \\
\hline
\end{tabular}

\section{CONCLUSÕES}

Em geral os habitantes da região do baixo Xingu consideram que os quelônios têm grande importância cultural, social e ambiental, sobretudo porque esses animais são utilizados como alimento e fonte de renda a partir do comércio ilegal, e desempenham diversas funções ecológicas como parte da teia alimentar, manutenção do equilíbrio ambiental, ciclagem de matéria orgânica e dispersão de sementes. Destacam os costumes e a falta de recursos financeiros como os principais motivos para os usos dos quelônios na região. Acreditam que os eventuais conflitos existentes entre quem faz uso dos quelônios e os agentes de fiscalização dos órgãos ambientais podem ser resolvidos por meio do diálogo e da garantia do direito ao consumo de subsistência. Reconhecem que as iniciativas conservacionistas desenvolvidas na região são eficazes, pois, garantem a reprodução por meio da proteção e manejos das áreas de nidificação e conscientizam as pessoas sobre a importância da conservação dos quelônios. Entretanto, afirmam que os estoques naturais diminuíram ou estão diminuindo, e percebem que a predação antrópica dos animais e ovos, bem como a degradação ambiental, são as principais ameaças à conservação desses répteis. Como meios para garantir a manutenção dos estoques naturais, recomendam o aumento da fiscalização sobre a captura/coleta/comércio ilegal dos quelônios e seus ovos, proteção e manejo das praias de desova, e a realização de ações de educação ambiental.

Os entrevistados estão dispostos a participar voluntariamente de ações para conservação dos quelônios, isso porque gostariam de manter esses animais para as gerações futuras ou porque caso contrário eles serão extintos. No entanto, boa parte não incentivaria familiares e amigos a não consumirem esses répteis, uma vez que considera difícil mudarem esse costume e muitos fazem isso por falta de renda. Esses resultados evidenciam que iniciativas de conservação devem ser planejadas levando-se em consideração aspectos culturais, sociais e econômicos da população local. Consequentemente, o envolvimento comunitário efetivo, a geração de alternativas de renda e ações de sensibilização por meio de esforços educacionais contínuos podem contribuir para recuperação e manutenção das espécies de quelônios e 
ecossistemas associados.

Conhecimentos e atitudes a respeito dos quelônios estiveram relacionados às características socioeconômicas dos entrevistados. A compreensão sobre a importância ambiental desses répteis foi mais elevada entre os participantes do presente estudo com maior renda, da mesma forma que a disposição em incentivar o não consumo de quelônios foi maior entre os mais jovens, com maior escolaridade, que não eram pescadores e que moravam na cidade. Diante disso, programas de conservação desenvolvidos na região devem considerar a possibilidade de adaptar suas estratégias de acordo com as características culturais, sociais e econômicas do público alvo, possibilitando com isso maior efetividade das ações e a otimização dos recursos investidos. Os resultados ainda sugerem que em razão do uso cultural como alimento e do comércio ilegal, os quelônios sofrem intensa pressão de caça na área estudada. Nesse sentido, estudos futuros devem avaliar a longo prazo os efeitos dos usos e consumo desses répteis sobre seus estoques naturais, assim como aprofundar o conhecimento sobre como as variáveis socioeconômicas influenciam os hábitos e atitudes dos habitantes locais em relação a esses animais. Também é recomendado que estudos de percepção ambiental sejam realizados periodicamente e assim se verifique quais aspectos das ações de conservação melhor contribuem para o gerenciamento eficaz dos recursos naturais.

AGRADECIMENTOS: À Universidade Federal do Tocantins - UFT através do Programa de Pós-Graduação em Ciências do Ambiente. À Norte Energia S. A. pelo apoio logístico prestado.

\section{REFERÊNCIAS}

AYRES, M.; AYRES, D. L.; SANTOS, A. A. S.; AYRES-JUNIOR, M.; AYRES, D.; SANTOS, A. A. S.. BioEstat 5.0: aplicações estatísticas nas áreas das ciências biológicas e médicas. Brasília: Sociedade Civil Mamirauá, 2007.

ALHO, C. J.; REIS, R. E.; AQUINO, P. P.. Amazonian freshwater habitats experiencing environmental and socioeconomic threats affecting subsistence fisheries. Ambio, v.44, n.5, p.412-425, 2015. DOI: https://doi.org/10.1007/s13280-014$\underline{0610-z}$

ALVES, R. R. N.; VIEIRA, K. S.; SANTANA, G. G.; VIEIRA, W. L. S.; ALMEIDA, W. O.; SOUTO, W. M. S.; MONTENEGRO, P. F. G. P.; PEZZUTI, J. C. B.. A review on human attitudes towards reptiles in Brazil. Environmental Monitoring and Assessment, v.184, n.11, p.6877-6901, 2012. DOI: https://doi.org/10.1007/s10661-011-2465-0

ATAÍDES, A. G.; MALVASIO, A.; PARENTE, T. G.. Percepções sobre o consumo de quelônios no entorno do Parque Nacional do Araguaia, Tocantins: conhecimentos para conservação. Gaia Scientia, v.4, n.1, p.07-20, 2010.

ATAÍDES, A. G.; MALVASIO, A.. Efeitos de práticas de Educação Ambiental sobre o conhecimento e atitudes em relação aos quelônios amazônicos, entre alunos de escolas públicas na região da bacia do Baixo Xingu (PA). Revista Brasileira De Educação Ambiental, v.14, n.4, p.185-203, 2019. DOI: https://doi.org/10.34024/revbea.2019.v14.9355

BALESTRA, R. A. M.. Recomendações de ações de educação socioambiental e proteção ambiental para a conservação de quelônios amazônicos. In: BALESTRA R. A. M.. Manejo conservacionista e monitoramento populacional de quelônios amazônicos. Brasília: IBAMA, 2016. p.111-115.

BARDIN, L.. Análise de conteúdo. Lisboa: Edições 70, 1977.

BAUER, M. W.; GASKELL, G.. Pesquisa qualitativa com texto, imagem e som. 2 ed. Petrópolis: Vozes, 2002.

BENNETT, N. J.. Using perceptions as evidence to improve conservation and environmental management. Conservation Biology, v.30, n.3, p.582-592, 2016. DOI: https://doi.org/10.1111/cobi.12681

CAMPOS-SILVA, J. V.; HAWES, J. E.; ANDRADE, P. C.; PERES, C. A.. Unintended multispecies co-benefits of an Amazonian community-based conservation programme. Nature Sustainability, v.1, n.11, p.650-656, 2018. DOI: https://doi.org/10.1038/s41893-018-0170-5

CANTARELLI, V. H.; MALVASIO, A.; VERDADE, L. M.. Brazil's Podocnemis expansa conservation program: Retrospective and future directions. Chelonian Conservation and Biology, v.13, n.1, p.124-128, 2014. DOI:

https://doi.org/10.2744/CCB-0926.1

CARVALHO, A. V.; LOPES, T. K. M.; MALVASIO, A.. Percepção ambiental dos projetos de conservação dos quelônios do Tocantins, Brasil. Nature and Conservation, v.9, n.1, p.6-12, 2016. DOI: https://doi.org/10.6008/SPC2318- 
2881.2016.001.0001

CASAL, A. C.; FORNELINO, M. M.; RESTREPO, M. F. G.; TORRES, M. A. C.; VELASCO, F. G.. Uso histórico y actual de las tortugas charapa (Podocnemis expansa) y terecay (Podocnemis unifilis) en la Orinoquia y la Amazonia. Biota Colombiana, v.14, n.1, p.45-64, 2013.

CONWAY-GÓMEZ, K.. Market integration, perceived wealth and household consumption of river turtles (Podocnemis spp.) in eastern lowland Bolivia. Journal of Latin American Geography, v.7, n.1, p.85-108, 2008. DOI: https://www.jstor.org/stable/25765200

COSTA, H. C.; BÉRNILS, R. S.. Répteis do Brasil e suas Unidades Federativas: Lista de espécies. Herpetologia Brasileira, v.7, n.1, p.11-57, 2018.

CRISTO, S. S.; BAIA JÚNIOR, P. C.; SILVA, J. S.; MARQUES, J. R. F.; GUIMARAES, D. A. A.. The trade of Kinosternon scorpioides on Marajo island, Brazilian Amazon: from hunting to consumption. Herpetological Journal, v.27, n.4, p.361-367, 2017.

DAMASIO, L. D. M. A.; CARVALHO, A. R.. Implications of consumption and ecological knowledge on the management of marine turtles on the Northern coast of São Paulo, Brazil. Bioikos, Campinas, v.24, n.2, p.95-104, 2012.

DITT, E. H.; MANTOVANI, W.; PÁDUA, C. V.; BASSI, C.. Entrevistas e aplicações de questionários em trabalhos de conservação. In: CULLEN JUNIOR, L.; RUDRAN, R.; PÁDUA, C. V.. Biologia da Conservação: Manejo da vida silvestre. Curitiba: Universidade Federal do Paraná, 2003. p.631-646.

EISEMBERG, C. C.; VOGT, R. C.; BALESTRA, R. A. M.; REYNOLDS, S. J.; CHRISTIAN, K. A.. Don't put all your eggs in one basket-Lessons learned from the largest-scale and longest-term wildlife conservation program in the Amazon Basin. Biological Conservation, v.238, 2019. DOI: https://doi.org/10.1016/j.biocon.2019.07.027

FACHÍN-TERÁN, A.. Participação comunitária na preservação de praias para reprodução de quelônios na Reserva de Desenvolvimento Sustentável Mamirauá, Amazonas, Brasil. Scientific Magazine UAKARI, v.1, n.1, p.19-30, 2008. DOI: http://dx.doi.org/10.31420/uakari.v1i1.3

FAGUNDES, C. K.; FATH, F.; CÔRTES, L. G.; GUIMARÃESJÚNIOR, R.; ANDRADE, P. C. M.; VOGT, R. C.; PEZZUTI, J. C. B.; MARCO JÚNIOR, P.. Vulnerabilidade dos sítios de desova das espécies-alvo do PAN Quelônios Amazônicos e efetividade de políticas públicas. In: LACAVA, R. V.; BALESTRA, R. A. M.. Plano de ação nacional para a conservação dos quelônios amazônicos. Brasília: IBAMA, 2019. p.61-88.

FARIA, V. A.; MALVÁSIO, A.. Aspectos sobre a caça, comercialização e consumo de quelônios na região do Corredor Ecológico Araguaia Bananal no Estado do Tocantins. Revista Ouricuri, v.8, n.2, p.026-048, 2018. DOI: http://dx.doi.org/10.29327/ouricuri.v8.i2.a3

FÉLIX-SILVA, D.; VIDAL, M. D.; JÚNIOR, J. B. A.; PEZZUTI, J. C. B.. Caracterização das atividades de caça e pesca na Floresta Nacional de Caxiuanã, Pará, Brasil, com ênfase no uso de quelônios. Biodiversidade Brasileira, v.9, n.2, p.232-250, 2019. DOI: https://doi.org/10.37002/biobrasil.v\%25vi\%25i.794

FERRONATO, B. O.; CRUZADO, G.. Uses, beliefs, and conservation of turtles by Ashaninka indigenous people, central Peru. Chelonian Conservation and Biology, v.12, n.2, p.308-313, 2013. DOI: https://doi.org/10.2744/CCB-1025.1

FERRARA, C. R.; FAGUNDES, C. K.; MORCATTY, T. Q.; VOGT, R. C.. Quelônios Amazônicos Guia de identificação e distribuição. Manaus: Wildlife Conservation Society Brasil, 2017.

FREITAS, C. T.; LOPES, P. F. M.; CAMPOS-SILVA, J. V.; NOBLE, M. M.; DYBALL, R.; PERES, C. A.. Co-management of culturally important species: A tool to promote biodiversity conservation and human well-being. People and Nature, v.2, n.1, p.61-81, 2020. DOI: https://doi.org/10.1002/pan3.10064

GOMES, R.. Análise e interpretação de dados de pesquisa qualitativa. In: MINAYO, M. C. S.. Pesquisa Social: teoria, método e criatividade. 25 ed. Petrópolis: Vozes, 2007.

GUEST, G.; BUNCE, A.; JOHNSON, L.. How many interviews are enough? An experiment with data saturation and variability. Field methods, v.18, n.1, p.59-82, 2006. DOI: https://doi.org/10.1177/1525822X05279903

IBGE. Instituto Brasileiro de Geografia e Estatística. Cidades. Brasília: IBGE, 2019.

IUCN. International Union for Conservation of Nature. The IUCN Red List of Threatened Species, Version 2018-2. Cambridge: IUCN, 2018.

KLEMENS, M. W.; THORBJARNARSON, J. B.. Reptiles as a food resource. Biodiversity \& Conservation, v.4, n.3, p.281298, 1995. DOI: https://doi.org/10.1007/BF00055974

LEWIS, E.; MANSFIELD, C.; BAUDAINS, C.. Going on a turtle egg hunt and other adventures: Education for sustainability in early childhood. Australasian Journal of Early Childhood, v.35, n.4, p.95-100, 2010. DOI: https://doi.org/10.1177/183693911003500412

LIKERT, R.. A technique for the measurement of attitudes. Archives of psychology, v.22, n.140, p.5-55, 1932.

MITTERMEIER, R. A.; BUHLMANN, K. A.; RHODIN, A. G. J.; PRITCHARD, P. C. H.. On the trail of giant river turtles. Reptiles Magazine, v.12, n.4, p.60-67, 2004.

MITTERMEIER, R. A.; VAN DIJK, P. P.; RHODIN, A. G.; NASH, S. D.. Turtle hotspots: an analysis of the occurrence of tortoises and freshwater turtles in biodiversity hotspots, highbiodiversity wilderness areas, and turtle priority areas. Chelonian Conservation and Biology, v.14, n.1, p.210, 2015. DOI: https://doi.org/10.2744/ccab-14-01-2-10.1

MOLL, D.; MOLL, E. O.. The ecology, exploitation, and conservation of river turtles. New York: Oxford University Press, 2004.

MORCATTY, T. Q.; VALSECCHI, J.. Social, biological, and environmental drivers of the hunting and trade of the endangered yellow-footed tortoise in the Amazon. Ecology and Society, v.20, n.3, p.1-10, 2015. DOI: 
http://doi.org/10.5751/ES-07701-200303

MORSE, J. M.. Designing funded qualitative research. In: NORMAN, K. D.; YVONNA, S. L.. Handbook of qualitative research. 2 ed. Thousand Oaks: Sage, 1994. p.220- 2335.

MORSE, J. M.. Determining sample size. Qualitative Health

Research, v.10, n.1, p.3-5, 2000. DOI:

https://doi.org/10.1177/104973200129118183

NORRIS, D.; MICHALSKI, F.. Socio-economic and spatial determinants of anthropogenic predation on Yellow-spotted River Turtle, Podocnemis unifilis (Testudines:

Pelomedusidae), nests in the Brazilian Amazon: Implications for sustainable conservation and management. Zoologia, Curitiba, v.30, n.5, p.482-490, 2013. DOI:

https://doi.org/10.1590/S1984-46702013000500003

NORRIS, D.; MICHALSKI, F.; GIBBS, J. P.. Community involvement works where enforcement fails: conservation success through community-based management of Amazon river turtle nests. Peer J., v.6, e4856, 2018. DOI:

https://doi.org/10.7717/peerj.4856

OCAMPO-GONZÁLEZ, P.; RODAS-TREJO, J.; HERNÁNDEZNAVA, J.; SOLÍS-MARROQUÍN, D.; CHANG-GUTIERREZ, D. Cultural consumption and social perception towards freshwater turtles in the Flora and Fauna Protection Area of Laguna de Términos, Campeche, México.

Agroproductividad, v.11, n.6, p.60-65, 2018.

PAULA, E. M. S. D.; SILVA, E. V. D.; GORAYEB, A.. Percepção ambiental e dinâmica geoecológica: premissas para o planejamento e gestão ambiental. Sociedade \& Natureza, v.26, n.3, p.511-518, 2014. DOI:

https://doi.org/10.1590/1982-451320140309

PÁEZ, V. P.; LIPMAN, A.; BOCK, B. C.; HEPPELL, S. S.. A plea to redirect and evaluate conservation programs for South America's podocnemidid river turtles. Chelonian Conservation and Biology, v.14, n.2, p.205-216, 2015. DOI: https://doi.org/10.2744/CCB-1122.1

PANTOJA-LIMA, J.; ARIDE, P. H.; OLIVEIRA, A. T.; FÉLIX-SILVA, D.; PEZZUTI, J. C.; REBÊLO, G. H.. Chain of commercialization of Podocnemis spp. turtles (Testudines: Podocnemididae) in the Purus River, Amazon basin, Brazil: current status and perspectives. Journal of Ethnobiology and Ethnomedicine, v.10, n.1, 2014. DOI: http://doi.org/10.1186/1746-4269-10-8

PARÁ. Plano de Desenvolvimento Regional Sustentável do Xingu. Belém: Secretaria de Estado de Integração Regional do Pará, 2010.

PARÁ. Plano Plurianual 2016-2019 do Governo do Estado do Pará. Belém: Secretaria de Estado de Planejamento do Estado do Pará, 2015.

PEGAS, F. V.; STRONZA, A.. Ecotourism and sea turtle harvesting in a fishing village of Bahia, Brazil. Conservation and Society, v.8, n.1, p.15-25, 2010. DOI:

http://doi.org/10.4103/0972-4923.62676

PEZZUTI, J. C. B.; FÉLIX-SILVA, D.; BARBOSA, R. S. L.; BARBOZA, M. S. L.; KNOGELMANN, C.; BARBOZA, R. S. L.; FIGUEIREDO, M. W.; ALCÂNTARA, A.; MARTINS, A.; COSTA, C. N.. Estudo de impacto ambiental do aproveitamento hidrelétrico (UHE) Belo Monte, rio Xingu. Componente: quelônios e crocodilianos. Relatório Final. Belém, 2008.

PEZZUTI, J. C.; LIMA, J. P.; SILVA, D. F.; BEGOSSI, A.. Uses and taboos of turtles and tortoises along Rio Negro, Amazon Basin. Journal of Ethnobiology, v.30, n.1, p.153-168, 2010. DOI: https://doi.org/10.2993/0278-0771-30.1.153

PEZZUTI, J.; CASTRO, F.; MCGRATH, D.; MIORANDO, P.; BARBOZA, R.; ROMAGNOLI, F. C.. Commoning in dynamic environments: community-based management of turtle nesting sites on the lower Amazon floodplain. Ecology and Society, v.23, n.3, p.36. DOI: https://doi.org/10.5751/ES10254-230336

REBÊLO, G.; PEZZUTI, J.. Percepções sobre o consumo de quelônios na Amazônia: sustentabilidade e alternativas ao manejo atual. Ambiente \& Sociedade, n.6-7, p.85-104, 2000. DOI: http://dx.doi.org/10.1590/S1414-753X2000000100005

RODRIGUES, M. T.. The conservation of Brazilian reptiles: challenges for a megadiverse country. Conservation biology, v.19, n.3, p.659-664, 2005. DOI:

https://doi.org/10.1111/j.1523-1739.2005.00690.x

RUEDA-ALMONACID, J. V.; CARR, J. L.; MITTERMEIER, R. A.; RODRÍGUEZ-MAHECHA, J. V.; MAST, R. B.; VOGT, R. C.; RHODIN, A. G. J.; OSSA-VELÁSQUEZ, J.; RUEDA, J. N.; MITTERMEIER, C. G.. Las tortugas y los cocodrilianos de los países andinos del trópico. Serie de Guías Tropicales de campo № 6. Conservación Internacional. Bogotá: Panamericana, Formas e Impresos, 2007.

SALERA JÚNIOR, G.; BALESTRA, R. A. M.; LUZ, V. L. F.. Breve histórico da conservação dos quelônios amazônicos no Brasil. In: BALESTRA, R. A. M.. Manejo conservacionista e monitoramento populacional de quelônios amazônicos. Brasília: IBAMA, 2016. p.11-14.

SCHNEIDER, L.; FERRARA, C. R.; VOGT, R. C.; BURGER, J.. History of Turtle Exploitation and Management Techniques to Conserve Turtles in the Rio Negro Basin of the Brazilian Amazon. Chelonian Conservation and Biology, v.10, n.1, p.149-157, 2011. DOI: http://doi.org/10.2744/ccb-0848.1

SCHNEIDER, L.; FERRARA, C. R.; VOGT, R. C.; SCHAFFER, C. Subsistence-level chelonian exploitation on the Rio Negro and one viable alternative. Chelonian Conservation and Biology, v.15, n.1, p.36-42, 2016. DOI: https://doi.org/10.2744/CCB-1188.1

SILVA, A. L.. Comida de gente: preferências e tabus alimentares entre os ribeirinhos do Médio Rio Negro (Amazonas, Brasil). Revista de Antropologia, v.50, n.1, p.125-179, 2007. DOI: https://doi.org/10.1590/S0034$\underline{77012007000100004}$

SILVA, D.; FACHÍN-TERÁN, A.; ROCHA, J.; JACAÚNA, C. Representações Simbólicas/Ambientais de atividades de conservação de quelônios por estudantes de escola ribeirinhas no Baixo Amazonas. Revista Educação Ambiental em Ação, v.11, n.41, 2012.

SILVA, M. A. P. P.; RODRIGUES, C. G. O.; ROBLES, R. A.. 'Tartarugada': uma iniciativa de sensibilização ambiental no Parque Nacional Marinho de Fernando de Noronha (PE). Revista Brasileira de Ecoturismo, v.6, n.5, p.1028-1051, 
2014. DOI: https://doi.org/10.34024/rbecotur.2013.v6.6341

SMITH, N. J.. Quelônios aquáticos da Amazônia: um recurso ameaçado. Acta Amazônica, v.9, n.1, p.87-97, 1979.

TISDELL, C.; WILSON, C.. Perceived impacts of ecotourism on environmental learning and conservation: turtle watching as a case study. Environment, Development and Sustainability, v.7, n.3, p.291-302, 2005. DOI: https://doi.org/10.1007/s10668-004-7619-6

VALLEJO-BETANCUR, M. M.; PÁEZ, V. P.; QUAN-YOUNG, L. I.. Analysis of People's Perceptions of Turtle Conservation Effectiveness for the Magdalena River Turtle Podocnemis lewyana and the Colombian Slider Trachemys callirostris in Northern Colombia: An Ethnozoological Approach. Tropical Conservation Science, n.11, p.1-14, 2018. DOI: https://doi.org/10.1177\%2F1940082918779069
VALSECCHI, J.; AMARAL, P. V.. Perfil da Caça e dos Caçadores na Reserva de Desenvolvimento Sustentável Amanã, Amazonas, Brasil. Scientific Magazine UAKARI, v.5, n.2, p.33-48, 2009. DOI:

http://dx.doi.org/10.31420/uakari.v5i2.65

VINUTO, J.. A amostragem em bola de neve na pesquisa qualitativa: um debate em aberto. Temáticas, Campinas, v.22, n.44, p.203-220, 2014. DOI:

https://doi.org/10.20396/temáticas.v22i44.10977

ZEPPEL, H.. Education and conservation benefits of marine wildlife tours: Developing free-choice learning experiences. The Journal of Environmental Education, v.39, n.3, p.3-18, 2008. DOI: https://doi.org/10.3200/JOEE.39.3.3-18

A CBPC - Companhia Brasileira de Produção Científica (CNPJ: 11.221.422/0001-03) detém os direitos materiais desta publicação. Os direitos referem-se à publicação do trabalho em qualquer parte do mundo, incluindo os direitos às renovações, expansões e disseminações da contribuição, bem como outros direitos subsidiários. Todos os trabalhos publicados eletronicamente poderão posteriormente ser publicados em coletâneas impressas sob coordenação da Sustenere Publishing, da Companhia Brasileira de Produção Científica e seus parceiros autorizados. Os (as) autores (as) preservam os direitos autorais, mas não têm permissão para a publicação da contribuição em outro meio, impresso ou digital, em português ou em tradução. 